\title{
International Symposium on
}

\section{New Techniques and Applications}

\section{in Libraries}

\author{
By Karen T. Wei \\ Chinese Librarian \\ University of Illinois at Urbana-Champaign
}

\begin{abstract}
An international exchange of experiences and expertise in China, September 8-11, 1988.
\end{abstract}

n China, as well as in many countries of the world, the needs for processing library materials and serving patrons in a most cost-efficient manner have become increasingly important. Recent developments in library and information technology in the West and their impact on improved services have attracted the attention of Chinese academic and research libraries. Although Chinese librarians are fully aware of the urgent needs in library automation, they have encountered some problems, particularly in standardization and the language barrier. Nevertheless, their enthusiasm and eagerness to learn the new technology have led them to international involvement.

In 1987, a symposium emphasizing mutual exchange of experiences and expertise among library professionals from the United States, China, and other parts of the world was initiated. It was organized by Hwa-wei Lee (United States), director of Ohio University Libraries and Zhang Zhiyu (China), director of Xian Jiaotong University Library, with the cooperation of Yoichi Terashi (Japan), director of the Center for Information Processing of the Kanazawa Institute of Technology. It was jointly sponsored by the three institutions represented by the three directors.

This international event convened at Xian Jiaotong University, Xian, Shaanxi Province, China, September 8-11, 1988. More than one hundred librarians and information scientists from Australia, Canada, Finland, Hong Kong, Japan, Thailand, the United Kingdom, the United States, and the People's Republic of China attended the four-day meeting. The scope and themes of the symposium included: 1) applications of modern technology in libraries and information centers; 2) design, use, and management of modern library and information facilities and resources; and 3) research on libraries, technologies, and services to better meet information needs.

There were sixteen keynote and invited papers and more than seventy contributed papers given in seventeen sessions of the meeting. In addition to the five keynote sessions, the contributed papers were divided into eight broad subjects: application of CD-ROM in the library, computer cataloging systems, computer circulation systems, the new library building of Xian Jiaotong University, library 
and information services, online information retrieval systems, library automation, and miscellaneous uses for computers in the library. Exhibitions were held simultaneously at the Xian Jiaotong University Library.

Among the North American participants, there were eight keynote papers delivered in five sessions covering a spectrum of new library techniques and their applications in libraries. The presentations focused on the roles of modern libraries in the information age, modern technology and its impact upon library facilities and services, and the effects of these innovations on library education, networking, preservation, and international cooperation. The keynote speakers and their papers presenting the academic and research library's view were: Margaret Beckman, executive director for Information Technology, University of Guelph, on "Implications of Technology for New Library Facilities"; Ching-chih Chen, associate dean and professor, Graduate School of Library and Information Science, Simmons College, on "Libraries in the Information Age: New Technology, New Media, New Mission, and New Challenge"; Bessie K. Hahn, library director, Brandeis University, on "Book Preservation: An International Agenda"; Donald E. Riggs, dean of University Libraries, Arizona State University, on "Expert Systems in Libraries"; Robert D. Steuart, dean and professor, Graduate School of Library and Information Science, Simmons College, on "Educating Information Professionals through Technology in the Curriculum"; and Theodore F. Welch, director of libraries and professor, Northern Illinois University, on "Participating in LCS: Northern Illinois University Libraries in the Statewide Library Computer System."

Offering the U.S. government's point of view were papers by D. E. Fossedal, Superintendent of Documents, U.S. Government Printing Office, on "Information to the People," and Thomas C. Phelps, senior program officer, U.S. National Endowment for the Humanities, on "The National Endowment for the Humanities Perspectives on PROJECT EMPEROR-I's Qin Terracotta Figures."

In addition, there were some twenty papers delivered by the U.S. participants. A special presentation and demonstration conducted by Chingchih Chen on "Interactive Video Discs and the First Emperor of China: A Case Presentation on PROJECT EMPEROR-I's Qin Terracotta Figures" highlighted the delegates visit to the famous Emperor Qin Shihuang's Mausoleum, which is under the protection of the Chinese government, some twenty-five miles east of Xian. The audio and video equipment used in the demonstration were subsequently donated to the Chinese officials.

During the four-day conference, library experi- ences were shared among the international participants and the Chinese hosts. Some personal observations: 1 ) the majority of the papers $(60 \%)$ were presented by Chinese colleagues; 2 ) most of the Chinese papers concentrated on the practical or experimental uses of the new technology, particularly microcomputers and CD-ROM; 3) Chinese librarians were more interested in the technical processing and circulation of library materials than direct user services; and 4) Chinese librarians were

\section{The White House Conference needs you!}

Did you ever wish that academic libraries received more recognition for their contributions to business and economic development? Are you seeing more and more common threads connecting academic libraries and computer centers? Do you see yourself increasingly as an information specialist needing to utilize nonprint resources as heavily as print information sources?

If you answered yes to any of those questions, it's time to become involved in local planning for the White House Conference on Library and Information Science II (WHCLIS). White House Conference II is scheduled for July 9-13, 1991, and will be preceded by regional and governors' conferences scheduled across the country during the next 18 months. A major goal of the ACRL Task Force on WHCLIS is to spark sufficient involvement among ACRL members to assure selection of at least one academic librarian delegate from each state.

The Conference itself consists of 900 delegates elected from states and territories. The delegates come from the following four sectors: the library and information profession, library supporters (trustees and friends), government officials, and the general public. During WHCLIS I in 1979, issues affecting academic libraries and librarians were not significantly visible. In order to ensure that this oversight is not repeated, ACRL members need to get involved now. You must convince your library friends, faculty, and staff to become involved as well.

The ACRL Task Force is drafting a position paper that will lay out the issues facing academic information specialists. Task Force members will depend upon ACRL Chapter members to react to the draft and assist in forming the final paper. A hearing is scheduled for ALA Annual Conference in Chicago to review and finalize the position paper.-Patricia A. Wand, Chair, ACRL WHCLIS Task Force. 
open-minded and eager to adapt themselves to the new technology.

The symposium was largely successful and demonstrated the importance of international cooperation and coordination. Hwa-wei Lee and Zhang Zhiyu's concerted efforts to bring this sym- posium to fruition were most appreciated. Without their wholehearted devotion this international conference would never have taken place in China. Finally, the hospitality of the Chinese hosts at the Xian Jiaotong University should be credited.

\section{Linking university library catalogs in Ontario}

Forty library directors and other library and information systems professionals met in Waterloo, Ontario, on November 19-20, 1989, to discuss the promises and opportunities for a provincial library network. Keynote speaker Johnny Wong, associate provost for computing and information systems at the University of Waterloo, described ONet, the Ontario Network, which links the major Ontario universities, two Ontario centers of excellence, the Ontario Centre for Large Scale Computation, and a commercial member.

The meeting was originally organized as an information session for senior library staff at the University of Waterloo, but interest spread rapidly to other administrators interested in the potential advantages of linked access to online catalogs.

The group heard presentations by Avi Schonbach (Geac Canada Ltd.), Richard Steele (Minicomputer Systems, Inc.), and Paul Nixon (Pendragon Optical Media Ltd.), who all concentrated on the possibilities for data sharing through standard communication protocols, network processors, or CD-ROM exchange.
A panel of specialists responded to the presentations. Ed Buchinski (National Library of Canada) urged closer attention to standards and to the high cost associated with ignoring standardization. Dora Dempster (Seneca College) emphasized the need to cross type-of-library boundaries; basic library services, she stressed, ought to be available to all users in the community regardless of affiliation. John Black (University of Guelph) suggested that library services should not be driven by technology, and that expedience may be contrary to long-term planning. Rosemary Kavanaugh (Ontario Ministry of Culture and Communications) is studying basic network services for Ontario through the Ontario Public Libraries Information Network.

Seminar organizer Murray Shepherd, university librarian at the University of Waterloo, indicated that considerable interest was generated among the participants and that some libraries will be meeting separately with each other and/or with the vendors to explore the means of proceeding with some experimental library links.

\section{RBMS Preconference in Minneapolis}

"The Next Decade: Issues Strategies, and Opportunities for Special Collections in the 1990s" is the theme of the 31st Preconference of the ACRL Rare Books and Manuscripts Section to be held in Minneapolis June 19-22. The papers will focus on such topics as ethics, collection development, copyright issues, preservation, strategic partnership, and institutional relationships. The beginning of the last decade of the 20th century provides an opportunity to reflect upon the past and speculate on the future of special collections and rare book librarianship. Both philosophical and practical concerns will be addressed by seven outstanding speakers in a series of seminars.
The plenary speakers and their topics are as follows: Millicent Abell, university librarian, Yale University, "Special Collections at the Turn-of-the Century"; Kenneth D. Crews, attorney, Los Angeles, California, "Copyright, Privacy, and Technology: Access to Rare Books and Unpublished Manuscripts"; Ellen S. Dunlap, director, Rosenbach Museum and Library, "Alliances or Dalliances: Considering Strategic Partnerships"; Beverly F. Lynch, dean, Graduate School of Library and Information Science, UCLA, "Ethical Standards and Practice: A Revision of a Statement of Standards"; John Parker, curator, James Ford Bell Library, University of Minnesota, "Red Canaries and a Cage 
Too Small"; Julian G. Plante, Founding Executive Director, Hill Monastic Library and Research Professor of Classics, St. John's University, Collegeville, Minnesota, "The Hill Monastic Library: Preserving the Past for the Future"; Micheal Ryan, Director of Library Collections and Curator of Special Collections, Stanford University, "Places for the Past in the Future: Developing Special Collections in the 90s."

The seminars will for the most part deal with procedural and technical issues such as revision to Bibliographic Description of Rare Books, writing a formal collection development policy for a special collection, the implications for special collections of preservation reformatting, and new developments in security products. There will also be sessions on controversial ethical issues facing special collections librarians, research uses that transform the nature of collections, and the reorganizing of existing space in response to changing needs.

The Preconference will open on Tuesday, June 19 , with a reception at the Wilson Library, University of Minnesota. Additional receptions will be held on Wednesday evening at the Minnesota Center for the Book Arts and on Thursday evening at the James J. Hill House. Also on Thursday participants will be taken by bus for a day trip to St. John's University and Abbey in Collegeville for a tour of the campus, some buildings of which were designed by Marcel Breuer, and the Hill Monastic Manuscript Library. A lunch and program events will also take place on this rural campus. After the trip back and the reception a dinner will be held at the Campus Club.
Registration is limited to the first 250 applicants. The registration fee of $\$ 125$ for ACRL members and $\$ 175$ for non-members must be included with the registration form. This fee includes entry to the preconference receptions and to all preconference papers and seminars. It also includes lunches at the hotel on Wednesday and Friday, the bus trip and lunch at St. John's University, and the dinner at the Campus Club on Thursday evening. Name badges and preconference materials may be picked up at the preconference registration at the Radisson University Hotel on Tuesday, June 19, from 3:00 p.m. to 7:00 p.m. or Wednesday, June 20, from 8:00 a.m. to 10:00 a.m. Written cancellations only will be honored until May 15 (minus a $\$ 25$ cancellation fee). Late registrations will be accepted on a spaceavailable basis after May 15 at an additional cost of $\$ 25$ per person.

The University Radisson Hotel is a pleasant facility located in the midst of the University of Minnesota and within ten minutes of downtown Minneapolis. The hotel provides free shuttle service to ares within a ten-mile radius. Rates are $\$ 68$ for single occupancy and $\$ 72$ for double occupancy. A housing form will be sent upon receipt of your registration. The cost of the hotel is not included in the preconference registration fee.

A brochure describing the preconference will be sent to all RBMS members by mid-March. Others who are interested in attending should contact: Mary Ellen Davis, American Library Association, ACRL, 50 East Huron Street, Chicago, IL 60611; (800) 545-2433.

\section{How to participate in ACRL}

\section{Information for new members and potential members.}

\section{To join}

Write or call the Association of College and Research Libraries for application forms and information: ACRL Office, 50 E. Huron, Chicago, IL 60611-2795; (800) 545-2433; in Illinois, (800) 5452444; in Canada, (800) 545-2455; or (312) 9446780 .

\section{To learn about ACRL's current programs, officers, and units}

Check the ALA Handbook of Organization and read College \& Research Libraries News regularly (as a member of ACRL, you will receive both publications). 